\title{
Seasonal variations in the lipid and fatty acid composition of the euphausiid Meganyctiphanes norvegica from the Ligurian Sea
}

\author{
Patrick Mayzaud*, Patti Virtue, Eric Albessard \\ Observatoire Océanologique, Océanographie Biochimique et Ecologie, ESA-CNRS 7076, BP 28, \\ 06230 Villefranche-sur-Mer, France
}

\begin{abstract}
Lipid and fatty acid composition of the northern krill Meganyctiphanes norvegica from the Mediterranean Sea were studied with respect to sex and season. Detailed composition of the lipid classes is reported for both males and fernales during the spring reproductive season and the late summer non-reproductive season. Both sexes showed similar lipid structure, with neutral lipids dominated by triacylglycerols. Polar lipids were dominated by phosphatidylcholine. Fatty acid compositions of both polar lipids and triacylglycerols showed little change with sex or season. Polar lipids were dominated by HUFA (20:5n-3 or EPA and $22: 6 n-3$ or DHA) as well as palmitic and oleic acid. Neutral lipid fatty acid profiles were dominated by 22:6(n-3) and palmitic acid, with a significant contribution of oleic, myristic, stearic and vaccenic acids as well as 20:5(n-3). Seasonal changes in total lipids showed maximum accumulation in early summer and minimum levels in early winter. Changes in fatty acid composition appeared related to the succession of populations with varying levels of triacylglycerols, as illustrated by the contrast between the early winter and spring periods in a correspondence analysis. Increased proportions of myristic, palmitoleic and 18:4(n-3) acids during the spring period are characteristic of the triglyceride fraction while the main descriptor of the winter period is DHA, which is the key constituent of the polar lipids. Comparison with literature data illustrated the clear decrease in lipid content of northern krill with latitude and the specific nature of the seasonal pattern recorded in the Ligurian Sea. The regional variability in fatty acid composition and the significance of fatty acids as potential markers of feeding behaviour are discussed in relation to the omnivorous character of $M$. norvegica.
\end{abstract}

KEY WORDS: Northern krill · Lipids · Ligurian Sea

\section{INTRODUCTION}

The northern krill Meganyctiphanes norvegica is known to occur in a wide range of habitats from the arctic waters to the Mediterranean Sea (Mauchline 1980). It is known to form a significant part of the arctic zooplankton biomass (Mauchline \& Fisher 1969) and to be an essential food source for fish and whales. Lipid studies on pelagic euphausiids have concentrated on the antarctic krill Euphausia superba (see Clarke 1980, Mayzaud 1997) and detailed biochemical analyses of $M$. norvegica have been reported mostly from Norwegian waters (Falk-Petersen 1981, FalkPetersen et al. 1981, Sargent \& Falk-Petersen 1981,

•E-mail: mayzaud@ccrv.obs-vlfr.fr
Saether et al. 1986). Fatty acid composition has been reported on few occasions from krill sampled at specific periods: fall (Ackman et al, 1970), early winter (Sargent \& Falk-Petersen 1981) or mid-winter (Belloni et al. 1976).

Data on the pattern of lipid accumulation and fatty acid structure of southern populations are, to a large extent, non-existent despite obvious differences in the characteristics of the physical and trophic environment. From an oceanographic point of view, the Mediterranean Sea is divided into a series of deep basins characterised by the dominance of evaporation over precipitation and river run-off (Bethoux 1979). This results in the formation of a deep water body with higher temperature and salinity than surrounding oceans. Meganyctiphanes norvegica is a northern cold 
water species which was isolated in the Mediterranean Sea at the closure of the basin and as a result developed adaptive strategies to cope with different hydroclimatic conditions and environment. Among those, the most obvious are the extensive diurnal vertical migration 1600 to $800 \mathrm{~m}$ compared to 80 to $200 \mathrm{~m}$ in northern waters) and the reproductive period which takes place in winter instead of summer (Cuzin-Roudy \& Buchholz 1999).

The concentration of lipids and mainly neutral lipids is determined by a balance between dietary intake, anabolism and catabolism. A large intake of lipids results in substantial deposition in the organism, so that fatty acid composition of tissue neutral lipids reflects that of the diet and can be used to probe predator-prey relationships. Consequently, individuals facing a very different environment may maintain the same trophic link or adapt and develop new strategies. In the Mediterranean Sea, the need to cope with an oligotrophic ecosystem, characterised by primary productivity mostly associated with the dynamics of frontal systems (Jacques \& Treguer 1986), is likely to result in changes in trophic interactions and thus in the patterns of lipid deposition and structure.

The present study was undertaken to partly fill this gap and to characterise the seasonal changes in lipid content and fatty acid structure of the Ligurian Sea (NW Mediterranean) population.

\section{MATERIAL AND METHODS}

Sampling. Individuals of Meganyctiphanes norvegica ( $M$. Sars) were collected at night with an IsaacKidd midwater trawl or an Omori-type net $11 \mathrm{~mm}$ mesh size). Sampling was done at a central station along the transect Villefranche-sur-Mer-Calvi in the Ligurian Sea. Oblique tows were made between $200 \mathrm{~m}$ and the surface. Adult stages were sorted on board, rinsed with distilled water and quickly frozen in liquid nitrogen The samples were usually brought back to the laboratory within $12 \mathrm{~h}$ and stored at $-70^{\circ} \mathrm{C}$ until analysis (usually within $4 \mathrm{mo}$ ). The seasonal survey was carried out during the 1978-1979 period and additional samples were obtained during the LIGEX 1 cruise (April 1996) and LIGEX 2 cruise (September 1997).

Size, weight measurements and lipid extraction. Entire krill were placed frozen on crushed ice and brought to $0^{\circ} \mathrm{C}$. Size (cephalothorax length) and fresh weight (WW) were measured prior to lipid extraction according to the method of Bligh \& Dyer (1959). For the seasonal survey, the lipids were extracted from pooled samples of adults (usually 15 to 20) and extracts weighed in tarred vials. Variability in lipid composition in relation to sex was established on single adults after sex and maturity stage determination. All lipid extracts were placed under nitrogen at $-70^{\circ} \mathrm{C}$ until analysis. Individual dry weight was recorded on sub-samples of 15 krill dried at $70^{\circ} \mathrm{C}$ for $6 \mathrm{~d}$.

Lipid analyses. Lipid classes were quantified after chromatographic separation coupled with FID (flame ionisation detector) detection on a Iatroscan Mark III TH 10 (Ackman 1981). Total lipid extracts were applied to chromarod SIII using microcapillaries (1 $\mu \mathrm{l})$ and analysed in duplicate. Neutral lipids were separated using a double development procedure with the following solvent systems: $n$-hexane:benzene:formic acid 80:20:0.5 (by volume) followed by $n$-hexane:diethylether:formic acid 97:3:0.5 (by volume). Calibration was achieved using commercial standards as well as polar lipids (phosphatidyl choline and phosphatidyl ethanolamine), and triacylglycerols purified from Meganyctiphanes norvegica by column chromatography and TLC (Mayzaud \& Albessard unpubl.). Fatty acid methyl esters of total lipids were prepared with $7 \%$ boron trifluoride in methanol (Morrison \& Smith 1964). Gas liquid chromatography (GLC) of all esters was carried out on a $48 \mathrm{~m}$ length $\times 0.25 \mathrm{~mm}$ internal diameter capillary column coated with Silar 5CP in a Perkin-Elmer Sigma 2 equipped with an FID and a Spectra-Physics SP4100 integrator. The column was operated isothermally at $165^{\circ} \mathrm{C}$. Helium was used as carrier gas at 60 psig ( 4 bars). Injector and detector were maintained at $250^{\circ} \mathrm{C}$. In addition to the examination of esters as recovered, a part of all ester samples was completely hydrogenated and the products examined qualitatively and quantitatively by GLC

LIGEX samples were analysed according to Virtue et al. (1999). Briefly, hydrocarbon, neutral and polar lipids were separated by column chromatography on silica gel (Bio-Sil HA, minus 325 mesh). These fractions were eluted with 6 column volumes of hexane, chloroform and methanol respectively. GLC was carried out on a Perkin-Elmer Autolab XL equipped with a $\mathrm{J}$ and $W$ fused silica capillary column (SE-30), an FID and a split injector system.

Statistical analyses. The allometric relations between dry weight (DW) and cephalothorax length (CTlength) for the different maturity stages (DW $=$ aCTlength ${ }^{b}$ ) was computed after log-log transformation and model I regression (Sokal \& Rohlf 1981). Correspondence analysis (Benzecri 1969, Gower 1987) was performed on a reduced data matrix transformed to relative frequencies and scaled so that each row (or column) can be viewed as a row (or column) of a conditional probability distribution. Only the 13 major fatty acids were considered, to achieve a matrix with the same number of variables and observations. Distances between profiles were computed with $\chi^{2}$ metrics. This distance gives symmetry to the 2 sets of data 
so that each factorial axis associated with the cluster of variables corresponds to a factorial axis of the cluster of observations. Thus, it was possible to represent simultaneously descriptors and observations on the plane defined by the factorial axes. Details on the method and means of interpretation are given in Mayzaud et al. (1988). To facilitate the representation of the factor-score structure, an ascending hierarchical clustering method was used (Lebart et al. 1995) to group those observations which displayed maximum similarity and to produce a number of classes best represented in a dendrogram. Computation of multivariate tests was made using the SPAD 3.0 software (Lebart et al. 1995).

\section{RESULTS}

\section{Size, weight and lipid relationships}

The weight relationships with size or lipid content over seasons were established for all stages present in the samples collected, i.e. subadults (CT-length $<8 \mathrm{~mm}$ ), males and females. The log-log regression between size and weight (Fig. 1) was highly significant $\left(\mathrm{R}^{2}=\right.$ $0.941 ; F_{1.25}=417$ ), with an allometric exponent of 3.03 indicative of isometric growth. Total lipid content was also correlated with the changes in dry weight $\left(\mathrm{R}^{2}=0.671 ; F_{1,25}=51\right)$ with an allometric exponent of 1.16 which suggested direct proportionality (Fig. 1).

\section{Lipid composition and seasonal changes in total lipids}

Detailed composition of the lipids are presented in Table 1 for samples of males and females of Meganyctiphanes norvegica collected during spring 1996 and early fall 1997. Lipid content (\% dry weight) fell within the range recorded earlier, with values marginally higher in spring than in fall for both sexes. Neutral lipids were dominated by triacylglycerols without traces of wax esters. Significant percentages of monoand diglycerides were recorded along with cholesterol, hydrocarbons, free fatty acids and diacylglyceryl ethers. Polar lipids were dominated by phosphatidyl choline and to a minor extent phosphatidyl ethanolamine and lysophophatidyl choline. Phosphatidyl serine and inositol were also present along with small percentages of phosphoglycerols. Despite the difference in sex and season, mean values in lipid composition
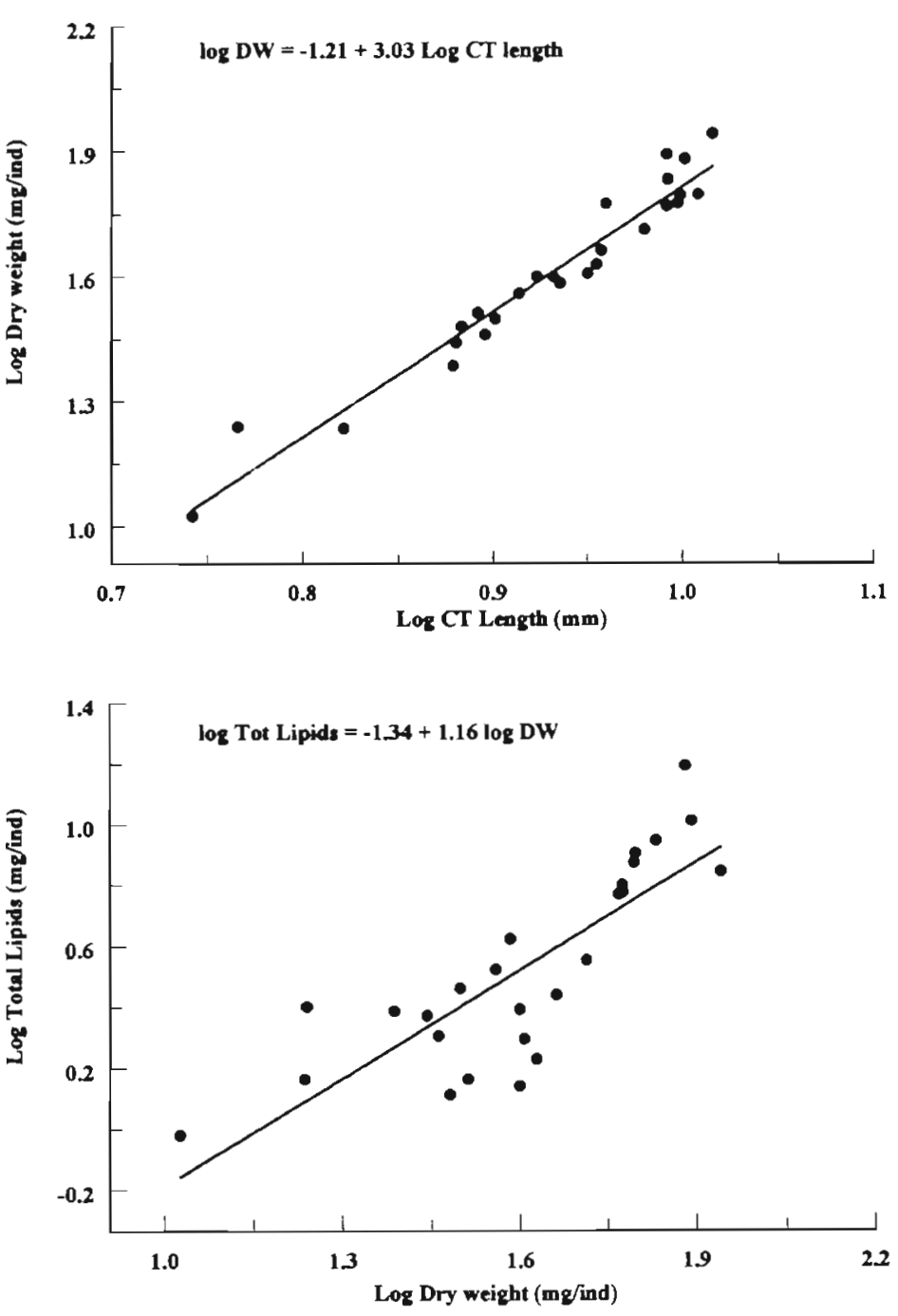

Fig. 1. Meganyctiphanes norvegica. Log-log regressions for subadults and adults between dry weight and cephalothorax length (CT-length) and between dry weight and total lipid content were not significantly different and suggest a relative homogeneity for the 2 months considered.

The changes in lipid concentration per unit dry weight were recorded from September 1978 to November 1979 and ranged from 3.5 to $20.5 \%$ (Fig. 2). Maximum accumulation was observed in early summer (June) and minimum values in early winter (December-January). Intermediate concentrations were recorded during the reproductive season (late winter to spring) and early fall.

\section{Fatty acid composition in relation to sex at specific periods}

The male and female samples collected during the 2 LIGEX cruises were also analysed for fatty acid com- 
Table 1. Meganyctiphanes norvegica. Composition of lipids in relation to sex and season. LIGEX 1: April 1996; LIGEX 2: September 1997

\begin{tabular}{|c|c|c|c|c|}
\hline \multirow[t]{2}{*}{ Lipid class } & \multicolumn{2}{|c|}{ Males $(n=10)$} & \multicolumn{2}{|c|}{ Females $(\mathrm{n}=10)$} \\
\hline & LIGEX 1 & LIGEX 2 & LIGEX 1 & LIGEX 2 \\
\hline Lipid content ( $\%$ dry weight) & $15.42 \pm 2.92$ & $11.03 \pm 4.23$ & $13.53 \pm 4.25$ & $10.64 \pm 3.95$ \\
\hline Hydrocarbons & $6.04 \pm 0.97$ & $5.13 \pm 2.01$ & $5.52 \pm 2.35$ & $4.90 \pm 2.12$ \\
\hline Triacylglycerols & $19.60 \pm 4.12$ & $22.74 \pm 9.84$ & $20.75 \pm 7.80$ & $19.18 \pm 11.42$ \\
\hline Free fatty acids & $4.72 \pm 3.11$ & $2.75 \pm 3.70$ & $1.22 \pm 1.83$ & $1.07 \pm 1.80$ \\
\hline Diacylglyceryl ethers & $1.09 \pm 1.51$ & $0.49 \pm 1.05$ & $0.31 \pm 0.82$ & $0.51 \pm 1.62$ \\
\hline Cholesterol & $9.02 \pm 1.28$ & $8.21 \pm 2.90$ & $7.77 \pm 1.53$ & $7.49 \pm 1.76$ \\
\hline Diacylglycerols & $9.74 \pm 1.50$ & $8.68 \pm 2.73$ & $8.96 \pm 1.82$ & $7.55 \pm 2.67$ \\
\hline Monoacylglycerols & $4.86 \pm 1.40$ & $1.53 \pm 1.85$ & $1.84 \pm 2.02$ & $2.64 \pm 2.76$ \\
\hline Phosphoglycerols & $0.82 \pm 0.10$ & $0.50 \pm 0.44$ & $1.10 \pm 0.25$ & $2.75 \pm 2.03$ \\
\hline Phosphatidyl ethanolamine & $7.28=0.84$ & $8.93 \pm 3.18$ & $9.20 \pm 1.80$ & $10.81 \pm 3.70$ \\
\hline Phosphatidyl serine + inositol & $1.88 \pm 0.78$ & $3.29 \pm 1.15$ & $2.06 \pm 1.13$ & $2.30 \pm 1.23$ \\
\hline Phosphatidyl choline & $29.61 \pm 5.22$ & $32.85 \pm 6.19$ & $34.15 \pm 4.90$ & $33.51 \pm 5.80$ \\
\hline Lysophosphatidyl choline & $5.35 \pm 0.58$ & $4.89 \pm 1.81$ & $7.12 \pm 4.28$ & $7.30 \pm 2.51$ \\
\hline
\end{tabular}

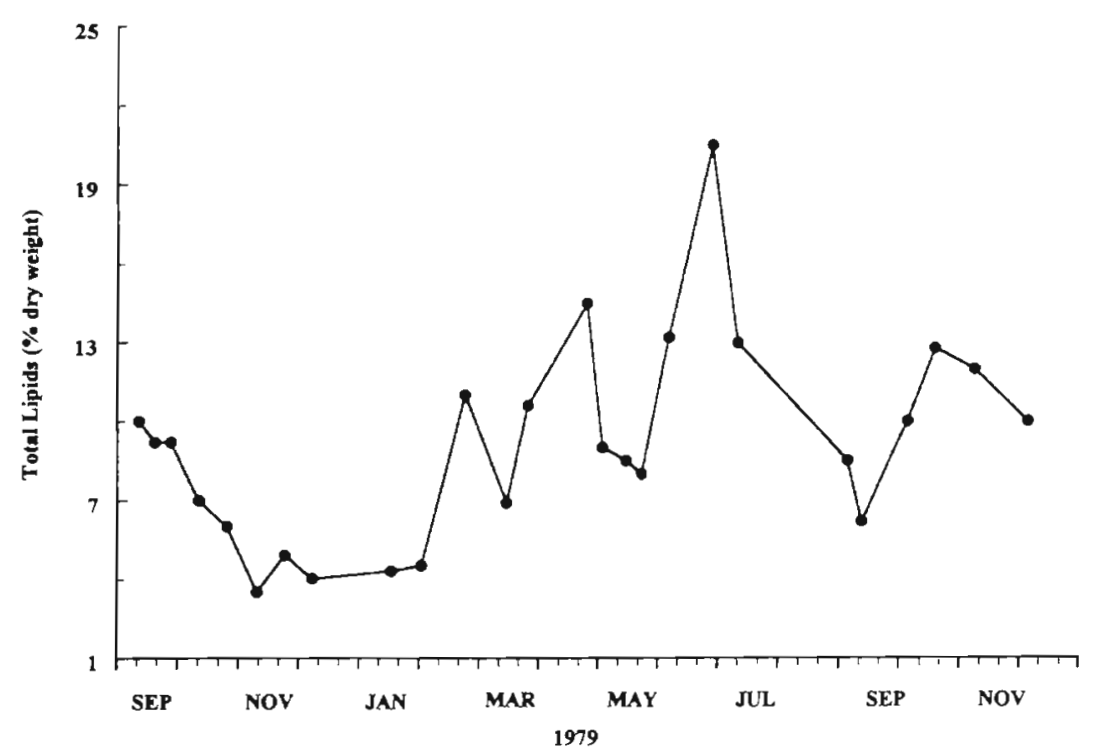

Fig. 2. Meganyctiphanes norvegica. Seasonal changes in total lipid content (\% dry weight) in the 1978-1979 period

palmitic acid, with significant contributions from oleic acid, myristic acid, EPA, stearic acid and vaccenic acid. The contribution of $20: 1$ acids, linoleic acid, $\alpha$-linoleic acid, 18:4n-3, and 18:5n-3 was small, but larger than in the phospholipid fraction. Differences between sampling periods can be seen in females in those fatty acids associated with nutritional activity: 18:0, 18:3, 18:4 (better represented in the April samples, LIGEX 1) and 18:5, 20:1, EPA and to a minor extent DHA (better represented in the September sample, LIGEX 2).

\section{Seasonal changes in the fatty acid composition of total lipids}

The relative composition of total fatty acids in Meganyctiphanes norvegica is presented in Table 2 .

position. The distribution of major fatty acids are presented in Fig. 3 and restricted to the major constituents $(>1 \%)$. As anticipated, the phospholipid fraction showed hardly any changes in composition with the period of sampling and none with sex. In all cases 22:6n-3 (DHA) dominated in association with 20:5n-3 (EPA), palmitic acid (16:0) and oleic acid (18:1n-9). Minor constituents comprised myristic acid (14:0), stearic acid (18:0), vaccenic acid $(18: 1 n-7)$, linoleic acid (18:2n-6) and $\alpha$-linoleic acid (18:3n-3). Triacylglycerol fatty acids showed a different pattern, but again few changes were found with respect to sex or sampling date. Distributions were dominated by DHA and
Regardless of the period considered, the fatty acids were dominated by high levels of DHA (21-38\%), palmitic acid (13-22\%), oleic acid (8-12\%) and EPA (9-21\%). Myristic acid (14:0), stearic acid (18:0), palmitoleic acid $(16: 1 n-7), 18: 1 n-7$, linoleic acid (18:2n-6) as well as 18:3n-3, 18:4n-3 and arachidonic acid (20:4n-6) were also present at levels higher than $1 \%$. Minor fatty acids comprised 20:1 and 22:1, 16:1n-9, 20:2n-6, C16 polyunsaturated acids, 20:4n-3 and 22:5n-3. Branch chain fatty acids comprised iso + anteiso acids with 15,16 and 17 carbons and ratios of iso/anteiso ranging from 1 to 8 . The seasonal changes affected mostly the DHA content, with maximum val- 
Fig. 3. Meganyctiphanes norvegica. Fatty acid composition (\% total fatty acids) of polar lipids and triacylglycerols for males and females collected during the spring reproducing period (LIGEX 1) and the late summer nonreproducing season (LIGEX 2)

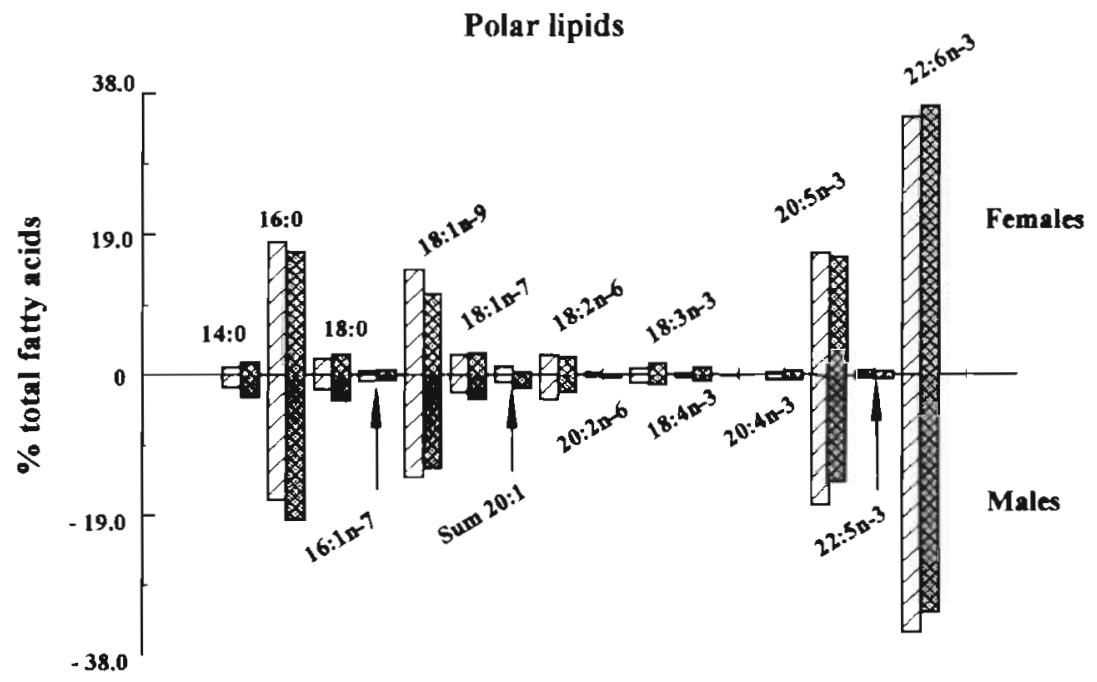

Triacylglycerols

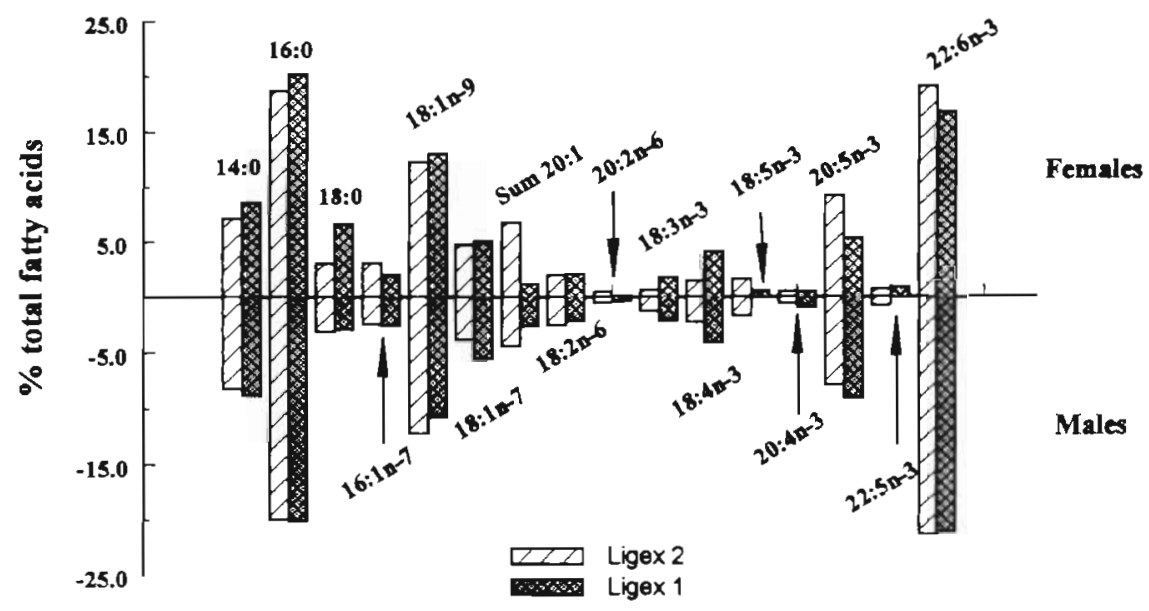

ues in early winter (December-January), palmitic acid and EPA, with high levels in spring of both years (April-May), and monoenoic acids, with maximum values in mid-spring (May 1978 and April 1979). The ratio iso/anteiso showed minimum levels in winter and reached maximum values in May and July. Ratios between monoenoic acids showed few seasonal changes. Ratios between 20:5 and 22:6 illustrated the dominance of DHA over EPA but with important seasonal changes. The ratio varied from almost 1 in early May to a minimum of 0.28 in August.

The seasonal changes in the pattern of fatty acid was analysed using multivariate correspondence analysis on the reduced data matrix. Three axes are needed to explain $90 \%$ of the total variance, with close to $80 \%$ associated with the first two. The projection of both fatty acid descriptors and date of observation on the plane defined by Axes 1 and 2 showed (Fig. 4) that the first axis $(48 \%$ of total iner- tia) separated on the one hand the early winter period (end of November to January) and on the other hand spring (April-May) (Fig. 4b) with 22:6(n-3), $20: 4(n-6), 18: 2(n-6)$ and $16: 1(n-7), 14: 0,18: 4(n-3)$ as respective descriptors (Fig. 4a). Axis 2 opposed 20:1 acids to EPA (20:5n-3), with no clear discrimination of specific periods. Axis 1 can be associated with the seasonal succession of populations with varying levels of triacylglycerols. Increased proportions of myristic, palmitoleic and 18:4(n-3) acids are characteristic of the triglyceride fraction (see Fig. 3) while DHA is the main constituent of the polar lipids. This interpretation agreed with the seasonal pattern of total lipids (Fig. 2), with minimum levels found from November to January and maximum levels in May and June. The second axis better described the trophic relationship as the fatty acid potential markers for copepods (Calanus type) and phytoplankton were the main descriptors. 
Table 2. Meganyctiphanes norvegica. Seasonal changes in the fatty acid composition of total lipids during the 1978-1979 period. Poly: polyunsaturated acids. nd: not detected

\begin{tabular}{|c|c|c|c|c|c|c|c|c|c|c|c|c|c|}
\hline Fatty acid & Apr 21 & May 2 & May 29 & Jun 14 & Jul 18 & Aug 18 & Nov 27 & Nov 30 & $\operatorname{Dec} 7$ & Jan 30 & Feb 22 & Apr 11 & Apr 25 \\
\hline $14: 0$ & 2.46 & 6.60 & 4.77 & 4.55 & 3.50 & 3.67 & 3.34 & 3.16 & 2.23 & 1.47 & 1.94 & 4.36 & 4.52 \\
\hline Iso $15: 0$ & 0.14 & 0.38 & 0.29 & 0.27 & 0.30 & 0.38 & 0.24 & 0.17 & 0.17 & 0.08 & 0.40 & 0.51 & 0.37 \\
\hline Anteiso $15: 0$ & 0.09 & 0.13 & 0.14 & 0.09 & 0.10 & 0.15 & 0.11 & 0.20 & 0.13 & 0.13 & 0.13 & 0.25 & 0.19 \\
\hline $15: 0$ & 0.72 & 0.75 & 0.93 & 1.06 & 0.74 & 0.76 & 0.77 & 1.21 & 0.62 & 0.53 & 0.66 & 1.14 & 1.12 \\
\hline Iso $16: 0$ & 0.14 & 0.25 & 0.21 & 0.09 & 0.12 & 0.23 & 0.21 & 0.09 & 0.08 & 0.09 & 0.20 & 0.25 & 0.12 \\
\hline Iso $17: 0$ & 0.14 & 0.12 & 0.28 & 0.17 & 0.39 & 0.22 & 0.37 & 0.17 & 0.22 & 0.21 & 0.06 & 0.25 & 0.37 \\
\hline Anteiso 17:0 & 0.08 & 0.07 & nd & 0.09 & nd & 0.22 & 0.16 & 0.12 & 0.11 & 0.08 & 0.10 & 0.12 & 0.18 \\
\hline $16: 0$ & 18.73 & 17.93 & 19.86 & 18.37 & 15.88 & 17.41 & 18.37 & 13.20 & 14.92 & 13.44 & 19.13 & 21.64 & 22.14 \\
\hline $17: 0$ & 0.84 & 0.99 & 1.12 & 0.87 & nd & 0.89 & 1.08 & 1.27 & 1.27 & 0.92 & 0.81 & 1.00 & 0.85 \\
\hline $18: 0$ & 1.81 & 1.95 & 2.36 & 2.23 & 2.11 & 1.91 & 2.14 & 2.12 & 1.94 & 2.00 & 2.06 & 2.22 & 2.05 \\
\hline $19: 0$ & nd & 0.06 & 0.07 & 0.17 & 0.07 & 0.11 & 0.05 & 0.30 & 0.30 & 0.19 & 0.19 & nd & nd \\
\hline $20: 0$ & 0.14 & 0.18 & 0.41 & 0.21 & 0.24 & 0.14 & 0.13 & 0.19 & 0.06 & 0.15 & nd & 0.18 & 0.24 \\
\hline Total saturates & 25.29 & 29.41 & 30.44 & 28.17 & 23.45 & 26.09 & 26.97 & 22.20 & 22.05 & 19.29 & 25.68 & 31.92 & 32.15 \\
\hline $16: 1 n-9$ & 0.56 & 0.49 & nd & 0.52 & nd & 0.37 & 0.43 & 0.67 & 0.12 & 0.27 & 0.06 & 0.75 & 0.97 \\
\hline $16: 1 n-7$ & 2.67 & 4.93 & 2.81 & 2.77 & 1.94 & 1.71 & 1.79 & 1.71 & 0.77 & 0.76 & 1.30 & 2.49 & 2.68 \\
\hline $16: 1 n-5$ & 0.14 & nd & nd & 0.17 & 0.35 & 0.59 & 0.11 & 0.07 & nd & nd & nd & 0.12 & 0.12 \\
\hline $18: 1 n-9$ & 11.71 & 8.22 & 11.02 & 9.85 & 10.94 & 11.51 & 9.98 & 8.65 & 12.33 & 11.49 & 9.41 & 11.24 & 12.18 \\
\hline $18: 1 n-7$ & 5.51 & 5.32 & 5.78 & 4.76 & 3.43 & 3.64 & 5.31 & 3.49 & 3.18 & 3.07 & 5.85 & 4.88 & 4.90 \\
\hline $19: 1 n-8$ & nd & nd & 0.21 & nd & 0.10 & 0.11 & 0.11 & 0.18 & 0.21 & 0.18 & 0.16 & 0.10 & 0.08 \\
\hline $20: 1 n-9$ & 0.82 & 0.48 & 3.48 & 1.98 & 3.11 & 2.45 & 0.58 & 0.39 & 0.77 & 0.56 & 0.38 & 0.42 & 1.30 \\
\hline $20: 1 n-7$ & 0.20 & 0.18 & 1.02 & 0.29 & 0.66 & 0.43 & 0.21 & 0.23 & 0.13 & 0.10 & 0.19 & 0.06 & 0.18 \\
\hline $22: 1 \mathrm{n}-11+13$ & 0.13 & 0.59 & 0.88 & 0.92 & 0.70 & 1.04 & nd & 0.24 & nd & 0.07 & nd & nd & nd \\
\hline Total monoenes & 21.74 & 20.21 & 25.20 & 21.26 & 21.23 & 21.85 & 18.52 & 15.63 & 17.51 & 16.50 & 17.35 & 20.06 & 22.41 \\
\hline $18: 2 n-6$ & 1.65 & 1.33 & 1.72 & 1.78 & 1.86 & 1.82 & 1.43 & 1.66 & 2.11 & 3.06 & 1.65 & 2.08 & 1.67 \\
\hline $20: 2 n-6$ & 0.40 & 0.18 & 0.40 & 0.33 & 0.37 & 0.32 & 0.21 & 0.31 & 0.37 & 0.42 & 0.22 & 0.30 & 0.18 \\
\hline Total dienes & 2.05 & 1.51 & 2.12 & 2.11 & 2.23 & 2.14 & 1.64 & 1.97 & 2.48 & 3.48 & 1.87 & 2.38 & 1.85 \\
\hline $16: 3 n-4$ & 0.28 & 0.37 & 0.56 & 0.17 & 0.48 & 0.29 & 0.59 & 0.27 & nd & 0.37 & 0.48 & 0.7 & 0.24 \\
\hline $18: 3 n-3$ & 1.38 & 0.89 & 1.38 & 1.34 & 1.35 & 1.11 & 0.98 & 1.11 & 1.03 & 0.97 & 1.50 & 2.23 & 1.96 \\
\hline $20: 3 n-3$ & 0.21 & 0.22 & 0.28 & 0.21 & 0.29 & 0.27 & 0.30 & 0.20 & 0.20 & 0.27 & 0.33 & 0.39 & 0.34 \\
\hline Total trienes & 1.87 & 1.48 & 2.22 & 1.72 & 2.12 & 1.67 & 1.87 & 1.58 & 1.23 & 1.61 & 2.31 & 3.36 & 2.54 \\
\hline $18: 4 n-3$ & 1.25 & 1.20 & 2.07 & 3.05 & 1.52 & 1.28 & 1.40 & 1.14 & 0.71 & 0.50 & 2.08 & 2.39 & 2.01 \\
\hline $20: 4 n-6$ & 1.54 & 1.32 & 1.26 & 1.03 & 0.92 & 1.32 & 1.66 & 2.70 & 2.70 & 2.60 & 1.78 & 1.56 & 1.20 \\
\hline $20: 4 n-3$ & 0.57 & 0.32 & 0.79 & 0.79 & 0.57 & 0.78 & 0.38 & 0.34 & 0.33 & 0.48 & 0.86 & 0.54 & 0.35 \\
\hline Total poly with 4 & 3.36 & 2.84 & 4.12 & 4.87 & 3.01 & 3.38 & 3.44 & 4.18 & 3.74 & 3.58 & 4.72 & 4.49 & 3.56 \\
\hline $20: 5 n-3$ & 16.85 & 21.10 & 10.56 & 10.84 & 10.87 & 9.40 & 16.20 & 15.60 & 11.95 & 13.24 & 14.78 & 12.42 & 13.02 \\
\hline $21: 5 n-3$ & nd & 0.19 & 0.15 & 0.07 & 0.07 & 0.06 & 0.21 & 0.08 & nd & 0.22 & 0.41 & 0.15 & 0.08 \\
\hline $22: 5 n-6$ & 0.45 & 0.60 & 0.53 & 0.49 & 0.79 & 0.61 & 0.51 & 0.95 & 1.19 & 1.09 & 0.56 & 0.30 & 0.08 \\
\hline $22: 5 n-3$ & 0.08 & 0.20 & 0.60 & 0.99 & 0.63 & 0.30 & nd & 0.54 & 0.06 & 0.44 & 0.38 & 0.08 & 0.08 \\
\hline Total poly with 5 & 17.38 & 22.09 & 11.84 & 12.39 & 12.36 & 10.37 & 16.92 & 17.17 & 13.2 & 14.99 & 16.13 & 12.95 & 13.26 \\
\hline $22: 6 n-3$ & 27.94 & 21.80 & 22.75 & 28.62 & 33.43 & 33.48 & 29.51 & 34.18 & 37.14 & 37.45 & 30.79 & 24.35 & 23.58 \\
\hline Iso/Anteiso & 2.47 & 3.75 & 5.57 & 2.94 & 8.10 & 2.24 & 3.04 & 1.34 & 1.96 & 1.81. & 2.87 & 2.73 & 2.32 \\
\hline $16: 1 n-7 / 16: 0$ & 0.14 & 0.27 & 0.14 & 0.15 & 0.12 & 0.10 & 0.10 & 0.13 & 0.05 & 0.06 & 0.07 & 0.12 & 0.12 \\
\hline $18: 1 n-7 / 18: 1 n-9$ & 0.47 & 0.65 & 0.52 & 0.48 & 0.31 & 0.32 & 0.53 & 0.40 & 0.26 & 0.27 & 0.62 & 0.43 & 0.40 \\
\hline $20: 5 n-3 / 22: 6 n-3$ & 0.60 & 0.97 & 0.46 & 0.38 & 0.33 & 0.28 & 0.55 & 0.46 & 0.32 & 0.35 & 0.48 & 0.51 & 0.55 \\
\hline
\end{tabular}

\section{DISCUSSION}

In spite of its central position in the pelagic community of the North Atlantic and the Mediterranean Sea, studies on the lipid composition and changes of Meganyctiphanes norvegica are to a large extent limited to its northern distribution. Raymont et al. (1969, 1971 ) reported the lipid concentration of krill populations from Norwegian and Scottish waters to range from $10-12 \%$ dry weight in March-April to $29 \%$ in October-November. This pattern was confirmed in a more comprehensive study by Båmstedt (1976) on krill populations from fjords in western Norway, with lipid concentrations in the 10 to $27 \%$ range showing winter maxima from October to March. These relatively high levels were related to ovary maturation which take place in that period of the year. Subsequent drops in lipid content were not solely attributed to spawning, 


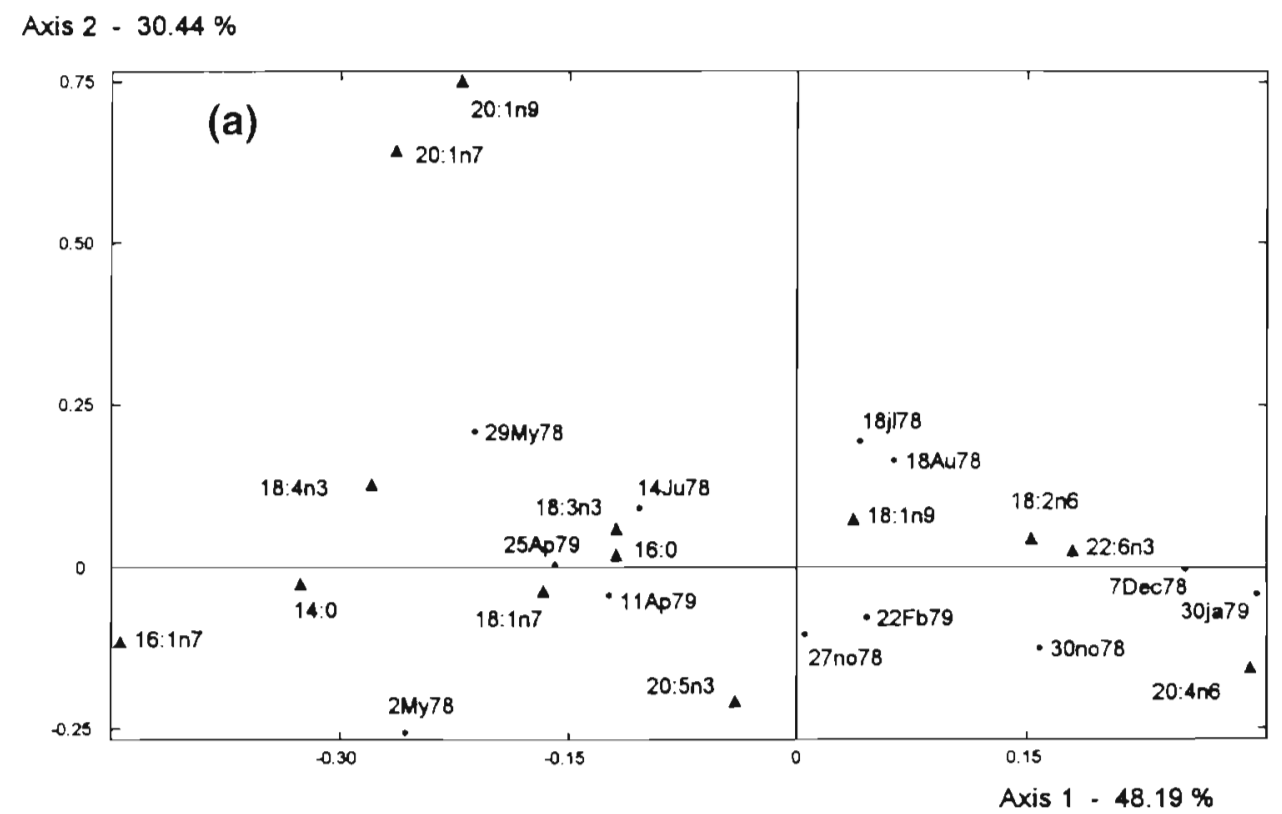

Fig. 4. Meganyctiphanes norvegica. Correspondence analysis of the seasonal changes in fatty acid composition of the total lipids. (a) Projection of fatty acid descriptors and date of sampling on the first 2 axes. (b) Dendrogram of hierarchical clustering of dates based on the scores of the first 5 factorial axes. ja: January; Fb: February; Ap: Aprili My: May; Ju: June; jl: July; Au: August; no: November; Dec: December (b)

but also to food scarcity at the end of winter. Later studies by Falk-Petersen (1981) and Buchholz \& PradoFiedler (1987) from northern Norway and Kattegat populations respectively also recorded a winter maximum, but showed different ranges of lipid content 7 to $48 \%$ for the Kattegat and 20 to $54 \%$ for northern Norway). According to Buchholz \& Prado-Fiedler (1987), lipid accumulation was closely related to food supply (mostly zooplankton) and these lipid reserves were used for metabolic needs rather than for gonad maturation and spawning.

The Ligurian Sea populations showed a very different and almost reverse pattern of seasonality, showing a late spring maximum and a winter minimum in lipid levels. The relationship between lipid concentrations and food supply was not directly analysed in this study; however the phytoplankton seasonality in the Ligurian Sea has been monitored in several studies and maximum chlorophyll is usually observed in late spring (April-May) in relation to the onset of vertical stratifica-

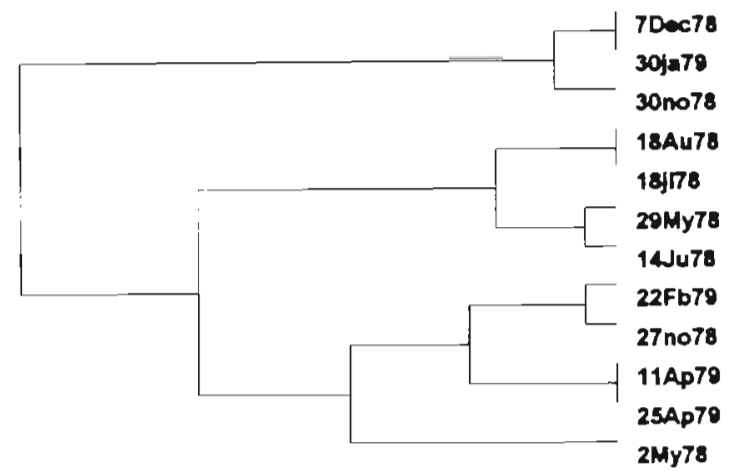

tion of the water column (de la Bigne 1985, Claustre et al. 1988/1989; Goffart et al. 1995) followed by an active period of zooplankton reproduction. De la Bigne (1985) evaluated the contribution of primary and secondary producers in the diet of Meganyctiphanes norvegica in the same study area and recorded the phytoplankton maximum as well as the increase in zooplankton biomass (mostly copepods collected with a WP 2 net: Calanus helgolandicus, Centropages typicus, Euchirella rostrata, etc.) in April. Maximum zooplankton biomass was generally recorded in spring and early summer (May). Summer and fall months (July to December) were characterised by low biomass of phytoplankton and low to intermediate concentrations of micro- and mesozooplankton. Thus, the increase in lipid content observed in June can be related to the April-May abundance of both primary and secondary producers. The rapid decrease in lipid content during summer and secondary accumulation in fall are indicative of the close relationship with food supply. The 
Table 3. Meganyctiphanes norvegica. Comparison of total lipid content (\% dry weight) from different geographical locations

\begin{tabular}{|lllll|}
\hline Region & Latitude $\left({ }^{\circ} \mathrm{N}\right)$ & Time of year & Lipid & Source \\
\hline Ligurian Sea & 43 & Sep 78-Dec 79 & 9.1 & Present study \\
Scottish water & 55 & Jan-Nov 68 & 17.2 & Raymont et al. (1971) \\
Kattegat & 57 & Mar-Sep 82 & 19.4 & Buchholz \& Prado-Fiedler (1987) \\
Norwegian west coast & 60 & Nov-May 66-67 & 18.4 & Raymont et al. (1969) \\
West Norway & 60 & Jul-Jul 73-74 & 17.5 & Bamstedt (1976) \\
North Norway & 70 & Nov-Jul 76-77 (small animals) & 37.0 & Falk-Petersen (1981) \\
& & Jan-Jul 76-77 (large animals) & 37.3 & \\
\hline
\end{tabular}

spring intermediate peak of total lipids (February to April) is directly related to gonad maturation and spawning rather than food scarcity (Cuzin-Roudy \& Buchholz 1999).

Comparison of mean lipid accumulation with geographical location (Table 3) suggested a north-south gradient with lower levels for the Ligurian Sea population and maximum values for the Norwegian subarctic populations. The larger accumulation of lipids at high latitudes has been emphasised by many authors for most zooplankters (see Benson \& Lee 1975, Conover \& Huntley 1991), but climatic conditions are only indirectly associated with such differences, which are more likely related to the pattern of food availability (Falk-Petersen 1981). High latitudes are characterised by extreme seasonality in light regime and thus in primary production, with a single intense phytoplankton bloom (>20 $\mathrm{\mu g}$ chlorophyll $\mathrm{l}^{-1}$ ) and zooplankton increase in biomass (Parsons \& Takahashi 1973, Nemoto $\&$ Harrison 1981). Northern temperate coastal waters showed moderate seasonality in light regime with 2 phytoplankton blooms (>10 $\mu \mathrm{g}$ chlorophyll $\left.\mathrm{l}^{-1}\right)$ and high zooplankton biomass throughout spring and summer (Parsons \& Takahashi 1973). Ligurian waters are nutrient limited and showed relatively constant low levels of zooplankton biomass and primary productivity, resulting in small blooms ( 1 to $3 \mu \mathrm{g}$ chlorophyll $\mathrm{l}^{-1}$ ). The reversal of the lipid seasonal cycle represented an adaptive response to (1) winter reproduction which allows the new generation to achieve growth dunng higher food abundance and (2) the need to cope with the summer food scarcity associated with the strong thermal stratification of the water column.

The lipid class composition of Meganyctiphanes norvegica has been described for subarctic populations only. Samples collected from the stomachs of whales caught in the North Atlantic Ocean contained polar lipids and triacylglycerols (Ackman et al. 1970) whereas sterols, triacylglycerols and wax esters were found by Falk-Petersen et al. (1981) in northern Norway samples. In the present study, neutral lipids contained cholesterol and triacylglycerols as well as diacylglyceryl ethers, mono- and diglycerides not reported previously. Free fatty acids comprised between 1 and $5 \%$ of the total lipids in the present study whereas high values (20 to $40 \%$ ) were recorded by Falk-Petersen et al. (1981), probably in relation to lipid hydrolysis. This is the first time that detailed polar lipid composition has been reported and it appeared relatively similar to that of Euphausia superba (Mayzaud 1997), with phosphatidyl choline as the dominant compound associated with smaller proportions of phosphatidyl ethanolamine as well as lysophosphatidyl choline. Small amounts of phosphoglycerols, phosphatidyl serine and phophatidyl inositol were also found. Falk-Petersen et al. (1981) reported that seasonal changes in total lipids were mostly accounted for by the variation in levels of triacylglycerols. A similar conclusion was reached by Virtue et al. (1999) for the Ligurian, Scottish and Kattegat krill populations. The lack of wax esters observed in the present study may be a direct reflection of a more omnivorous feeding behaviour of krill in the Ligurian Sea and/or the dominance of copepod prey poor in wax esters.

The comparison made in this study of the fatty acid composition of Meganyctiphanes norvegica from different locations is limited to the data from the North Atlantic (Ackman \& Eaton 1967, Ackman et al. 1970, Morris 1972), Northern Norway (Sargent \& FalkPetersen 1981, Saether et al. 1986), the Clyde Sea and the Kattegat (Virtue et al. 1999) and the Ligurian Sea (Belloni et al. 1976, this study using mean values over seasons). This comparison was made using correspondence analysis performed on a data matrix limited to those fatty acids listed in Table 2 of Sargent \& FalkPetersen (1981). Total fatty acid profiles were used whenever available. Triacylglycerols and polar lipid fatty acid profiles were also used on 4 occasions to define the boundaries which could be associated with the contribution of these 2 lipid classes. Axis 1 clearly discriminated between polar lipids and triacylglycerols from northern latitudes while Axis 2 separated the different samples in accordance with their abundance in 20:5 and 22:6 fatty acids, i.e. polar lipids versus triacyl- 
Axis 2 - $16.5 \%$

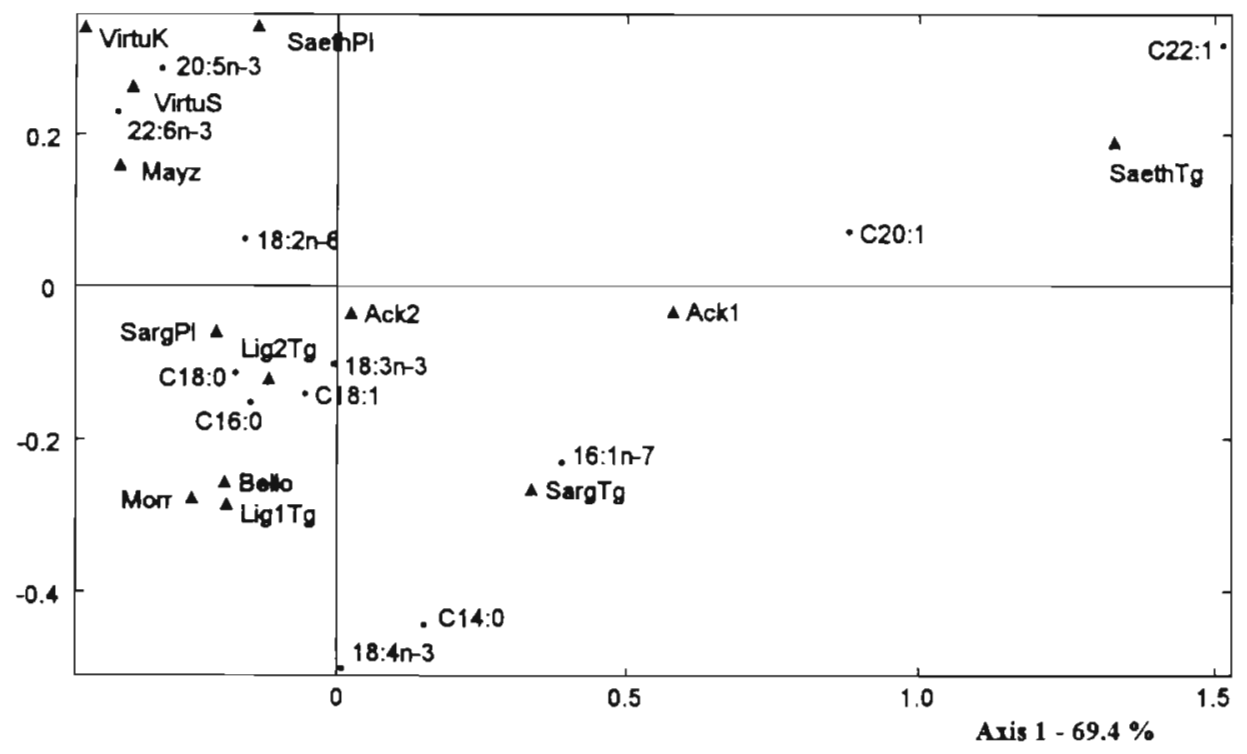

Fig. 5. Meganyctiphanes norvegica. Correspondence analysis of the fatty acid composition of polar lipids, triacylglycerols and total lipids published for different oceanic or coastal regions from the subarctic to the Mediterranean Sea. Pl: polar lipids; Tg: triacylglycerols; Mayz: mean fatty acid from total lipids in present study; Bello; total lipids, Belloni et al. (1976); Morr: total lipids, Morris (1972); Ack1: total lipids, Ackman \& Eaton (1967); Ack2: total lipids, Ackman et al. (1970); Saeth: polar lipids and triacylglycerols, Saether et al. (1986); Sarg: polar lipids and triacylglycerols, Sargent \& Falk-Petersen (1967); Lig 1 and Lig 2: triacylglycerols from LIGEX 1 and LIGEX 2 present study; VirtuK: polar lipids from the Kattegat, Virtue et al. (1999); VirtuS: polar lipids from the Clyde Sea, Virtue et al. (1999)

glycerols from the Ligurian Sea individuals (Fig. 5). The first axis was strongly associated with the fatty acid profiles of triacylglycerols from northern Norway (Saether et al. 1986) which were richer in 20:1 and 22:1 acids than any triacylglycerols or total lipids from other locations. Axis 2 was associated with the total lipid fatty acid mean profile from the present study, the polar lipid fatty acid profiles from the Clyde Sea and the Kattegat (Virtue et al. 1999) and northern Norway (Saether et al. 1986) which displayed a higher degree of unsaturation than total lipids or polar lipids from other locations. Such differences in total lipid unsaturation could be related either to a different contribution of the triacylglycerol fraction or to the sampling or analytical protocols used or to variability related to geographical location. The large difference in triacylglycerol fatty acid profiles between northern and Mediterranean sites suggests that the mean total fatty acid profile observed in this study presented little influence from any triacylglycerol component. In contrast, the fatty acid composition recorded by Belloni et al. (1976) for a different sector of the Ligurian Sea and Morris (1972) showed a large imprint from a triacylglycerol component with Ligurian characteristics (i.e. low percentage of monoenes having 20 and 22 carbons), indicative of regional differences associated with the structure of the food web. The position of the Sar- gent \& Falk-Petersen (1981) polar lipid fraction on the low unsaturation side of Axis 2 suggests that the large pool of free fatty acid recorded may well originate from the hydrolysis of the phospholipid fraction.

Could the fatty acid structure of Meganyctiphanes norvegica lipids provide some insight into the feeding behaviour of the Ligurian populations? Fatty acids, to some degree, can be used as potential trophic markers. Classically, diatom-dominated phytoplankton are rich in $16: 1 \mathrm{n}-7$ associated with $18: 1 \mathrm{n}-7$ fatty acids (Sargent \& Falk-Petersen 1981), a dominance of EPA over DHA and C16 polyunsaturated acids (Ackman et al. 1964). Dinophyceae (dinoflagellates), Haptophyceae (coccolithophorids), Prymnosiophyceae (Phaeocystis spp.), Chlorophyceae and Prasinophyceae (green microalgae) are rich in C18 polyunsaturated acid (Joseph 1975, Volkman et al. 1981, Claustre et al. 1989, Dunstan et al. 1992). Myristic acid (14:0) is a prominent fatty acid in diatoms and coccolithophorids (Ackman et al. 1964, 1968, Volkman et al. 1981) and is usually absent from the polar lipids of pelagic consumers (Sargent \& Whittle 1981). Calanoid copepods containing wax esters are usually characterised by significant quantities of monoenoic acids in 20 and 22 carbons (Pascal \& Ackman 1976), and animals feeding on large calanoids showed unusually high levels of these acids in their neutral lipids. Diet-induced changes in fatty 
acids have been tested experimentally. Graeve et al. (1994), using phytoplankton cultures, confirmed the nature of $16: 1 n-7,18: 1 n-7$, and $16: 3$ as an index of a diatom diet and $18: 4 n-3$ as an index of dinoflagellate food source. Using large-scale mesocosms, Fraser et al. (1989) showed that the fatty acid transfer from phytoplankton (diatoms, Dinophyceae and other nanoplankton) to copepods was better traced by changes in $18: 4 n-3$. If the interpretation of these indices is relatively simple for phytoplankton consumers, one should exercise caution when considering omnivorous species since fatty acid markers may be mixed (simultaneous ingestion of phytoplankton and zooplankton prey) and/or affected by the stomach content of the prey ingested. Few studies have considered fatty acid transfer in a multilevel food web; Mayzaud et al. (1976) showed that from dinoflagellate to carnivorous chaetognaths feeding on copepods the content in 18:5 in the neutral lipid fraction dropped from $10 \%$ in phytoplankton to $2 \%$ in the neutral lipids of herbivorous copepods, to $0.2 \%$ in the neutral lipids of the carnivorous consumer. Some degree of catabolism at each trophic level is likely to explain this decrease, which could be expected in a natural food-limiting situation. Fraser et al. (1989), using an experimental food web which comprised phytoplankton, copepods and fish larvae, concluded that the use of fatty acids as an indicator of herring larvae feeding was difficult because of the necessity of an accurate definition of the fatty acid content of the food organisms. To be of practical use under natural conditions, fatty acid tracers in omnivorous species should at least be present at concentrations higher than $1 \%$ of the total fatty acids (below that the tracer is likely to be a contaminant from ingested grazers) and display over time a pattern coherent with that of the food supply.

On the basis of the above considerations, different periods characterised by one or several trophic markers could be considered in the present study. In spring (April-May) maximum levels of $16: 1 n-7$ and $18: 1 n-7$ were recorded in agreement with the increase in phytoplankton usually observed at the same period and followed by a summer increase in 20:1n-9 from May to August. Seasonal changes in myristic acid (14:0) were also strongly correlated with those of $16: 1 \mathrm{n}-7$ ( $\mathrm{r}=0.802$, $\mathrm{n}=13$ ) confirming the above conclusion. For the rest of the year, other species of copepods or zooplankton without wax esters provided the bulk of the food items, but were not readily traceable from the fatty acid pattern. In the sampling area, which encompasses the geostrophic frontal system, the major food items were copepods such as Calanus helgolandicus, Euchirella rostrata, Centropages typicus (Boucher 1984) as well as several smaller cyclopoid species (Oithona sp., Oncaea $\mathrm{sp}$, etc.). The low levels of polyunsaturated C16 fatty acids and 18:4n-3 suggested that, although phytoplankton was part of the diet in spring and part of summer, the contribution of diatoms was associated with that of copepods. The dominance of $22: 6 n-3$ over $20: 5 n-3$ in the neutral lipids reinforces this conclusion as a dominant diatom food source would have resulted in a reverse proportion. Nevertheless, the changes in the ratio 20:5/22:6 were positively correlated $(r=0.814, n=13$ ) with the changes in 16:1n-7, suggesting that an increase in the 16:1n-7 marker of phytoplankton was associated with an increase in the proportion of 20:5n-3. More direct evidence of phytoplankton feeding has been obtained from chlorophyll gut content analyses and digestive enzyme activity such as laminarinase, which covaried with the period of maximum biomass of phytoplankton (de la Bigne 1985, Mayzaud \& Bedo unpubl. data). We conclude that in its southern limit of distribution Meganyctiphanes norvegica is largely omnivorous, feeding opportunistically on the dominant available items. At the other extreme, the subarctic populations were shown to be mostly carnivorous (Sargent \& Falk-Petersen 1981) and used the copepod Calanus finmarchicus as the major prey item. The fattyacid-derived trophic status of Atlantic temperate regions is more complex, with either carnivorous traits (Ackman et al. 1970; Virtue et al. 1999 in the Kattegat) or omnivorous features (Virtue et al. 1999 for the Clyde Sea). This complexity confirms the high degree of adaptability of this species to extremely diverse environmental conditions.

Acknowledgements. This study forms part of the project Impact of a climatic gradient on the physiological ecology of a pelagic crustacean' (PEP) of EU-MAST III program, contract no. MAS3-CT-0013. We would like to thank the captain and the crew of the FS 'Heincke' and of the RV 'Korotneff' We are also grateful for the technical assistance of $\mathrm{Mr} \mathrm{J}$. Chiaverini and $M$. Boutoute.

\section{LITERATURE CITED}

Ackman RG (1981) Application of flame ionization detectors to thin layer chromatography on coated quartz rods. Methods Enzymol 72:205-252

Ackman RG, Eaton CA (1967) Fatty acid composition of the decapod shrimp Pandalus borealis in relation to that of the euphausiid Meganyctiphanes norvegica. J Fish Res Bd Can 24:467-471

Ackman RG, Jangaard PM, Hoyle RJ, Brockerhoff H (1964) Origin of marine fatty acids. I. Analyses of the fatty acids produced by the diatom Skeletonema costatum. J Fish Res Bd Can 21:747-756

Ackman RG. Tocher CS, McLachlan J (1968) Marine phytoplankters fatty acids. J Fish Res Bd Can 25:1603-1620

Ackman RG, Eaton CA, Sipos JC, Hooper SN, Castell JD (1970) Lipids and fatty acids of two species of North Atlantic krill (Meganyctiphanes norvegica and Thysanoessa inermis) and their role in the aquatic food web. $\mathrm{J}$ Fish Res Bd Can 27:513-533 
Båmstedt U (1976) Studies on the deep-water pelagic community of Korsfjorden, western Norway. Changes in the size and biochemical composition of Meganyctiphanes norvegica (Euphausiacea) in relation to its life cycle. Sarsia 61:15-30

Belloni S, Cattaneo R, Pessani D (1976) Determinazione di acidi grassi in Meganyctiphanes norvegica (Sars, 1857) (Crustacea: Euphausiacea) del Mar Ligure. Boll Mus Ist Biol Univ Genova 44:103-112

Benson AA, Lee RF (1975) The role of wax in oceanic food chains. Sci Am 232:77-86

Benzecri JP (1969) Statistical analysis as a tool to make pattern emerge from data. In: Watanabe S (ed) Methodology of pattern recognition. Academic Press, New York, p $35-74$

Bethoux JP (1979) Budgets of the Mediterranean Sea. Their dependence on the local climate and on the characteristics of the Atlantic waters. Oceanol Acta 10:141-158

Bligh EG, Dyer JR (1959) A rapid method of total lipid extraction and purification. Can J Biochem Physiol 37:911-917

Boucher J (1984) Localization of zooplankton populations in the Ligurian marine front: role of ontogenic migration. Deep-Sea Res 31:469-484

Buchholz F, Prado-Fiedler R (1987) Studies on the seasonal biochemistry of the northern krill Meganyctiphanes norvegica in the Kattegat. Helgol Meeresunters 41: 443-452

Clarke A (1980) The biochemical composition of krill Euphausia superba Dana from south Georgia. J Exp Mar Biol Ecol 43:221-236

Claustre H, Marty JC, Cassiani L, Dagaut J (1988/1989) Fatty acids dynamics in phytoplankton and microzooplankton communities during a spring bloom in the coastal Ligurian Sea: ecological implication. Mar Microb Food Webs 3 $51-66$

Claustre H, Marty JC, Cassiani L (1989) Intraspecific differences in the biochemical composition of a diatom during a spring bloom in Villefranche sur Mer bay, Mediterranean Sea (France). J Exp Mar Biol Ecol 129:17-32

Conover RJ, Huntley M (1991) Copepods in ice covered seas Distribution, adaptation to seasonally limited food, metabolism, growth pattern and life strategies in polar seas J Mar Syst 2:1-41

Cuzin-Roudy J, Buchholz F (1999) Ovarian development and spawning in relation to the moult cycle in Northern krill, Meganyctiphanes norvegica (Crustacea:Euphausiacea), along a climatic gradient. Mar Biol 133:267-272

de la Bigne C (1985) Etude du métabolisme nutritionnel et des variations spatio-temporelles de l'environnement trophique potentiel de Meganyctiphanes norvegica. Thèse de Doctorat de l'Université Pierre et Marie Curie, Paris

Dunstan GA, Volkman JK, Jeffrey SW, Barrett C (1992) Biochemical composition of microalgae from the green algal classes Chlorophycae and Prasinophycae. 2. Lipid classes and fatty acids. J Exp Mar Biol Ecol 161:115-134

Falk-Petersen S (1981) Ecological investigation on the zooplankton community of Balsfjorden, Northern Norway. Seasonal changes in body weight and the main biochemical composition of Thysanoessa inermis, T. raschii and Meganyctiphanes norvegica in relation to environmental factors. J Exp Mar Biol Ecol 49:103-120

Falk-Petersen S, Gatten RR, Sargent RJ, Hopkins CCE (1981) Ecological investigation on the zooplankton community of Balsfjorden, Northern Norway. Seasonal changes in the lipid class composition of Meganyctiphanes norvegica, Thysanoessa raschii and T. inermis. J Exp Mar Biol Ecol $54: 209-224$
Fraser AJ, Sargent JR, Gamble JC, Seaton DD (1989) Formation and transfer of fatty acids in an enclosed marine food chain comprising phytoplankton, zooplankton and herring (Clupea harengus) larvae. Mar Chem 27:1-18

Goffart A, Hecq JH, Prieur L (1995) Contrôle du phytoplancton du bassin Ligure par le front liguro-provençal (secteur Corse). Oceanol Acta 18:329-342

Gower JC (1987) Introduction to ordination techniques. In: Legendre P, Legendre L (eds) Development in numerical ecology. NATO ASI Series G14:3-64

Graeve M, Kattner G, Hagen W (1994) Diet-induced changes in the fatty acid composition of Arctic herbivorous copepod. Experimental evidence of trophic markers. J Exp Mar Biol Ecol 182:97-110

Jacques G, Treguer P (1986) Les écosystèmes pélagiques. Masson, Paris

Joseph JD (1975) Identification of 3, 6, 9, 12, 15- octadecapentaenoic acid in laboratory cultured photosynthetic dinoflagellates. Lipids 10:395-403

Lebart L, Morineau A, Piron M (1995) Statistique exploratoire multidimensionnelle. Dunod, Paris

Mauchline J (1980) The biology of mysids and euphausiids Adv Mar Biol 18:1-681

Mauchline J, Fisher LR (1969) The biology of euphausiids. Adv Mar Biol 7:1-454

Mayzaud P (1997) Spatial and life cycle changes in lipid and fatty-acid structure of the antarctic euphausiid Eupausia superba. In: Battaglia B, Valencia J, Walton DWH (eds) Antarctic communities. Cambridge University Press, Cambridge, p 284-294

Mayzaud P, Eaton CA, Ackman RG (1976) The occurrence and distribution of octadecapentaenoic acid in a natural plankton population: a possible food chain index. Lipids $11: 858-862$

Mayzaud P, Albessard E, Cuzin-Roudy J (1988) Changes in lipid composition of the Antarctic krill Euphausia superba in the Indian sector of the Antarctic Ocean: influence of geographical location, sexual maturity stage and distribution among organs. Mar Ecol Prog Ser 173:149-162

Morris RJ (1972) The preservation of some oceanic animals for lipid analysis. J Fish Res Bd Can 29:1303-1307

Morrison WR, Smith LM (1964) Preparation of fatty acid methyl esters and dimethylacetals from lipids with boron fluoride-methanol. J Lipid Res 5:600-608

Nemoto T, Harrison G (1981) High latitude ecosystems. In: Longhurst A (ed) Analysis of marine ecosystems. Academic Press, New York, p 95-126

Parsons TR, Takahashi M (1973) Biological oceanographic processes. Pergamon Press, Oxford

Pascal JC, Ackman RG (1976) Long chain monoethylenic alcohol and acid isomers in lipids of copepods and capelin. Chem. Phys Lipids 16:219-223

Raymont JEG, Srinivasagam T, Raymont JKB (1969) Biochemical studies on marine zooplankton. VI. Investigation on Meganyctiphanes norvegica (M. Sars). Deep-Sea Res 16: $141-156$

Raymont JEG, Srinivasagam T, Raymont JKB (1971) Biochemical studies on marine zooplankton. VIII. Further investigation on Meganyctiphanes norvegica (M. Sars). DeepSea Res 18:1167-1178

Saether O, Ellingsen TE, Mohr V (1986) Lipids of north Atlantic krill. J Lipid Res 27:274-285

Sargent JR, Falk-Petersen S (1981) Ecological investigations on the zooplankton community in Balsfjorden Northern Norway: lipids and fatty acids in Meganyctiphanes norvegica, Thysanoessa raschi and $T$. inermis during mid winter. Mar Biol 63:131-137 
Sargent JR, Whittle KJ (1981) Lipids and hydrocarbons in the marine food web. In: Longhurst $A$ (ed) Analysis of marine ecosystems. Academic Press, New York, p 491-533

Sokal RR, Rohlf FJ (1981) Biometry. Freeman and Co, New York

Virtue P, Mayzaud P, Albessard E, Nichols P (1989) The use of

Editorial responsibility: Otto Kinne (Editor),

Oldendorf/Luhe, Germany fatty acids as dietary indicators in krill, Meganyctiphanes norvegica, from North Eastern Atlantic, Kattegat and Mediterranean during summer and winter. Can J Fish Aquat Sci (in press)

Volkman JK, Smith DJ, Eglinton G, Forsberg TEV, Corner EDS (1981) Sterol and fatty acid composition of four marine haptophycean. J Mar Biol Assoc UK 61:509-527

Submitted: January 7, 1999; Accepted: April 14, 1999 Proofs received from author(s): September 10, 1999 